\title{
CORPUS Corpus
}

Archivos virtuales de la alteridad americana

Vol 1, No 2 | 2011

Julio / Diciembre 2011

\section{Las Malvinas según Lorenz: Memorias en disputa de una guerra reciente}

Sergio Andrés Kaminker

\section{OpenEdition}

Journals

Electronic version

URL: http://journals.openedition.org/corpusarchivos/1143

DOI: 10.4000/corpusarchivos.1143

ISSN: $1853-8037$

\section{Publisher}

Diego Escolar

Electronic reference

Sergio Andrés Kaminker, «Las Malvinas según Lorenz: Memorias en disputa de una guerra reciente », Corpus [En línea], Vol 1, No 2 | 2011, Publicado el 30 diciembre 2011, consultado el 19 abril 2019. URL: http://journals.openedition.org/corpusarchivos/1143; DOI : 10.4000/corpusarchivos.1143

This text was automatically generated on 19 April 2019

Licencia Creative Commons: Atribución-NoComercial 2.5 Argentina (CC BY-NC 2.5 AR) 


\title{
Las Malvinas según Lorenz: Memorias en disputa de una guerra reciente
}

\author{
Sergio Andrés Kaminker
}

1 Las guerras por Malvinas; Fantasmas de Malvinas, un libro de viajes; y Malvinas, una guerra argentina forman una tría-da bibliográfica que condensa sentidos, sensibilidades e incomodidades del historiador Federico Lorenz en el tratamiento académico, político y social que se le da a la guerra de Malvinas de 1982, su historia y memoria, tan marginalmente pensada y elaborada desde la academia, con contadas excepciones ${ }^{1}$, y con plena vigencia por ser uno de los pocos eventos principales de nuestra historia reciente cuya memoria aún se encuentra en disputa.

2 Nación, territorio, colonialismo, juventud son algunas de las claves para comprender la dificultad para tratar los significados que las islas Malvinas tienen y tenían para casi todos los sectores políticos y sociales de la Argentina, como también la dificultad de codificar la guerra como tal sin el supuesto riesgo de aparentar ser un chauvinista o un apólogo de la dictadura que llevó a ella.

3 El esfuerzo de Lorenz por poner cada cosa en su sitio respectivo, no despegar la guerra de la dictadura, los ex combatientes de la experiencia que los convirtió en tales, las responsabilidades, algarabías y silencios sociales sobre los hechos, ni las diferencias vivenciales regionales, nos llevan a un escenario complejo donde la historia, nuestra memoria y forma de ver a Malvinas no vuelven a ser las mismas. Perdemos ingenuidad y recuperamos conciencia a través de la visibilidad que cobran, en estas obras, tanto los relatos de ex combatientes como los espacios regionales argentinos donde la guerra se vivió en forma mucho más intensa por la proximidad al escenario bélico, o el familiar que no se sabía si retornaba.

4 Al discutir en contra de falsas dicotomías en la interpretación de este evento, Lorenz nos acerca a la guerra de Malvinas en forma compleja, sensible y didáctica con tres libros que no se repiten ni se pisan, que escapan al maniqueísmo y nos permiten comprender otras dimensiones de nuestra historia reciente. 
$5 \quad$ Nuestra intención es recuperar algunos núcleos del planteamiento de Lorenz en estos tres libros -que consideramos fundamentales para la comprensión de la guerra de Malvinasno sólo en términos de lo que su-cedió en ese terreno específico en los 74 días que duró la misma, sino los significados de la forma en que recordamos, reivindicamos y comprendemos a las islas Malvinas, como un episodio paradigmático y problemático de nuestra historia reciente. Nos proponemos recorrer estos tres libros, reseñando algunas imágenes centrales de los mismos para graficar la importancia de tratar con fineza un tema espinoso de nuestra historia e identidad nacional argentina como es la guerra de Malvinas de 1982 y su memoria.

\section{Tres libros diferentes y complementarios}

6 Los tres libros en cuestión son autocalificados por el autor como libros de historia, por el contenido, pero sobre todo por la disciplina de formación y el carácter de las conclusiones y reflexiones en las que se detiene. Sin embargo, con fines de estimular una posible lectura de estos, arriesgamos una clasificación no apegada a géneros literarios, ni disciplinas, pero sí a las formas que estos documentos toman y sus implicancias para la comprensión de las guerras por Malvinas. Para ello, nos detendremos en cada uno de ellos por separado, para luego tratarlos como un todo. Dado que los vemos como reflexiones y desarrollos diferentes pero complementarios, antes que contraponer sus dichos, nos interesa remarcar algunas cuestiones centrales que tratan y resuelven y, por ende, su especificidad.

7 Antes que nada, queremos explicitar que la mayor diferencia entre estos libros es la forma que adquieren. La biografía de Lorenz, los relatos de otros, las imágenes narrativas y el análisis historiográfico adquieren pesos específicos distintos en la trama de cada uno de ellos, si bien luego de leerlos uno puede comprender de manera más acabada no sólo Malvinas, la guerra y sus disputas posteriores, sino también la relación del investigador con su tema de estudio.

8 Por una cuestión heurística y para repasar la propia lectura, comenzaremos cronológicamente. El primero de estos tres libros, publicado en 2006, fue Las guerras por Malvinas. Este es, probablemente, el más académico de los tres, con un formato claro y analítico. Lorenz se encarga de tematizar distintos aspectos del conflicto de 1982, sus consecuencias, significados y disputas en forma compleja y sostenida, no como un mero epifenómeno político de la última dictadura militar derivado de la decisión homicida de un alcohólico y partícipes de la represión ilegal que buscaron ganar popularidad.

9 Ante el riesgo de caer en cierto nacionalismo vulgar o victimización radical de los ex combatientes, Lorenz logra hacer una lectura amplia y desprejuiciada de las experiencias de guerra de los conscriptos ex combatientes, de los oficiales veteranos, de poblaciones cercanas al escenario de la guerra y de las distintas consecuencias que desencadenaron "guerras" sobre los sentidos e imágenes que, con el correr de los años, se dieron alrededor del conflicto.

10 La heterogeneidad es la marca que recorre todo el libro. En este sentido es que el autor marca que su intención no fue relatar la guerra de Malvinas en un sentido unívoco, "sino de las distintas formas en que ésta fue vivida, y de sus consecuencias, como una forma de pensar las relaciones entre la cultura y política argentinas y el archipiélago emblema" (2006, p. 15). Con un vasto trabajo de recopilación y análisis de fuentes orales y escritas, el 
foco del autor está puesto, fundamentalmente, en desentrañar esta multiplicidad de conflictos que se dieron con el final de la guerra el 14 de junio de 1982. Recupera, para esto, relatos de lo más variados, desde entrevistas a distintos ex combatientes, que fueron al conflicto siendo conscriptos que estaban realizando el servicio militar obligatorio, hasta informes oficiales de las propias fuerzas, medios de prensa y libros emblemáticos como el del ex comandante en jefe de las Fuerzas Armadas, veterano de la guerra, y actual embajador en Colombia, el general retirado Martín Balza.

11 El desarrollo del texto atraviesa una de las cuestiones centrales que permiten comprender el lugar que se le dio a Malvinas y a los ex combatientes: la gran mayoría de los que combatieron en las Islas Malvinas eran "colimbas", jóvenes entre los 18 y los 20 años, con poca o nula formación militar en su mayoría, a los cuales se vio llenos de virtudes y "puros", tomando la responsabilidad cívica de defender la soberanía nacional en la posible victoria, o inexpertos y víctimas en la derrota final. Lorenz se encarga de mostrar que estos sentidos que se le dieron, vinculados a cierto nacionalismo inculcado históricamente desde las escuelas, la derrota militar y la crisis del régimen durante el cual se llevó a cabo el asesinato de miles de jóvenes con la represión ilegal, permitieron estas imágenes históricas.

12 Sin embargo, a través de los relatos individuales de los ex combatientes, recupera cierta complejidad histórica $(2006$, p. 97) y señala que, lejos de sentirse pasivos y me-ras víctimas, ellos vivieron experiencias en las cuales no reniegan de su lugar de agencia, remarcando que no eran meros espectadores y que la ida al conflicto y las muertes tuvieron sentido. Es en las tensiones y contradicciones constantes, que se expresaron en diversas formas ${ }^{2}$, entre la represión ilegal de la dictadura, la condena de la violencia estatal, las desapariciones y Malvinas como símbolo y experiencia, que comenzó a darse la disputa por la visibilidad de los ex combatientes y los veteranos de guerra como colectivos al interior de la sociedad, entre procesos de "desmalvinización" y "malvinización" que se dieron desde iniciativas de distintas organizaciones de ex combatientes, de los gobiernos democráticos y las Fuerzas Armadas, con importante incidencia social hasta que se logró, según Lorenz, el ingreso, en la década del noventa en el "Panteón" de los héroes militares de la nación argentina (2006, p. 223), dentro de un pro-ceso de asimilación del conflicto llevado a cabo desde el gobierno de Menem. Remarca que este último, si bien suspendió el servicio militar obligatorio, reconoció ciertos derechos a los ex combatientes, incluyendo a oficia-les y suboficiales de las FFAA, buscando devolverle a estas ese lugar simbólico y prestigioso perdido luego de la dictadura.

13 Es en esos años que se comenzaron a dar los significativos regresos de familiares y ex combatientes a las islas, pero también la recuperación de los relatos de guerra de aquellos que habían estado 3 . Por último, analiza en forma interesante los significados y la particularidad de ciertos monumentos y recuperaciones más recientes de la, ahora, "gesta" de Malvinas, la cual es recuperada con algún grado de positividad "patriótica" (2006, pp. 234-235), aunque no descarta que sigue existiendo en el imaginario colectivo cierta victimización que operó sobre todo en los años ochenta, por lo que confirma que "la guerra y sus protagonistas oscilan entre dos extremos in-accesibles a la discusión: el limbo de las víctimas, o el Panteón atemporal de los héroes y mártires de la Patria" (2006, p. 237).

14 Con Las guerras por Malvinas, Lorenz se instala como una referencia ineludible por su aporte para comprender la trama histórica que llevó al conflicto en su especificidad, el 
apoyo y responsabilidades sociales en torno al mismo, así como sus sentidos y memoria, pero también la última dictadura militar, las Fuerzas Armadas y la violencia en la Argentina. En cambio, en Fantasmas de Malvinas. Un libro de viajes, editado en el 2008, Lorenz nos permite "volver a Malvinas" junto a él, como forma de "volver a pensar la Argentina" (2008, p. 165) apelando y cuestionando, con cierta vehemencia, la mirada que podamos tener sobre el conflicto. En esta invitación nos advierte,

Si un historiador especialista en la guerra de Malvinas escribe un libro sobre su viaje a esas islas, ¿el resultado es un libro de Historia? Creo que sí: fueron mi sensibilidad, mi formación y mi información sobre un tema los que me hicieron elegir unos lugares y no otros, unas miradas por sobre otras posibles (2008, p. 19).

El libro es una crónica de viaje que, mediada por años de trabajo de campo y relatos, el viaje y su oficio, termina deviniendo en un "libro de historia". Sin embargo, Fantasmas de Malvinas pierde el tono académico del libro anteriormente retratado, aunque no su densidad y profundidad, para ir y venir no sólo entre las islas y el continente, sino entre los relatos de distintas personas, sus memorias y la narración, sensación y sensibilidad de Lorenz, quien transparenta sus posiciones, sus ideas sobre la guerra, los sobrevivientes e, incluso, la memoria de los muertos, fundamentando sus incomodidades, ya no sólo en el plano disciplinar de la historiografía o de las ciencias sociales, sino terciando en las peleas sobre políticas de memoria para Malvinas.

Si Las guerras por Malvinas nos permite revisar las formas en que se recuerda el conflicto y los jóvenes que participaron del mismo, este libro nos obliga a tomar posición con respecto a la memoria, sus caídos y sus sobrevivientes. Claro que este último cobra mayor sentido si conocemos algo más del conflicto que lo que aparece y apareció históricamente en los medios y en los discursos oficiales. En este sentido, podemos decir que la virtud del libro, y su defecto, es que, al pendular entre la crónica y la historia, por momentos hila muy fino en discusiones sin explicitar demasiado sus contendientes y contenidos específicos. Por ello, resulta complementario con los otros dos libros. Lorenz explicita que "él tampoco es el mismo desde que volvió a las islas" y su compromiso con muertos y vivos, ex combatientes y familiares, se encarna y vuelve imagen en un espacio geográfico que aún sin presencia física, se encuentra virtualmente territorializado por aquellos a quienes la experiencia de la guerra dejó marcas indelebles. Allí hay recuerdos, fotos y huellas que unos y otros dejan, físicamente, pero también en los mapas del Google Earth, en distintas narraciones que, por conocer, Lorenz nos permite recorrer y reencontrar junto a él.

17 Si tuviéramos la suerte y la condena de poder viajar a las islas, Fantasmas de Malvinas sería una guía para volver a un sitio en el cual nunca estuvimos, que nos re-clamaría -con varias voces y formas- darle el lugar que le corresponde a la guerra en nuestra memoria, si bien, como señala Lorenz, "Los fantasmas, a diferencia de las prisiones del dolor, no nos obligan a nada. Están allí para reclamarnos discreción en el silencio y la palabra sobre sus historias, si solo hablar es lo que haremos respecto a ellas" (2008, p. 136). En él, a riesgo de sonar nacionalista y "cipayo" según quien lo mire, Lorenz afirma:

Yo estoy orgulloso de muchas de las cosas que vivió y protagonizó mi pueblo, y avergonzado y dolorido por otras tantas, pero antes que tirar todo a la basura prefiero dedicarme a aportar para separar la paja del trigo, para que entre otras cosas ningún asesino sea contrabandeado entre los que deberíamos honrar. Pero, también, para que re-conozcamos y respetemos con la misma intensidad a los que sintieron que todo era un despropósito y una locura, y se opusieron a eso y enfrentaron la condena social por no cumplir con ese mismo deber, porque también hubo que ser muy valiente para eso (2008:21). 

expresiones biográficas, las emociones que logra generar, sino también por las posturas que explicita, la vehemencia de las formas y los lugares a los que, como lectores, nos obliga a situarnos.

Ahora bien, yendo al último de los tres libros que nos propusimos reseñar, Malvinas. Una guerra argentina, podemos aseverar que, así como planteamos que los tres trabajos generan cierta complementariedad, el último de estos, publicado en 2009 por Editorial Sudamericana, da cuenta del recorrido de los otros dos. Si bien podemos decir que lo radical del libro de viajes, para alguien no tan conocedor del conflicto, se corporiza a través de la lectura de los otros dos libros, el tercero de ellos es una buena condensación histórica del conflicto destinada a un público más amplio. Adolece de referencias bibliográficas y biográficas excesivas, de extensas citas de autoridad o incluso de largos relatos, pero no por error de Lorenz, sino por el contrario, por acierto, por decantación o madurez de su propia mirada. Este es el libro más claro y ágil de los tres. Menos historiográfico que Las guerras por Malvinas en su forma de narrar, no por ello menos fino y profundo en su argumentación, logra poner en cuestión el lugar de los archipiélagos en nuestra construcción histórica de la nación, en nuestras deudas a pagar con el pasado, hasta hacernos comprender cómo aquello que nosotros podíamos ver como una guerra de liberación, los isleños vivieron "como una ocupación” (2009, p. 14).

Lorenz da cuenta de que no es ni "un escritor a sueldo de los británicos", ni "reivindicador de la dictadura" por traer a colación cómo fue experimentada la guerra por británicos o por ex combatientes, todos los cuales la vivieron como un parte aguas que tuvo sentido en sus vidas. De esta manera, el autor aborda en este libro cuáles eran las condiciones en las cuales se encontraba la última dictadura militar antes de ir a la guerra, y cómo, en los primeros años de democracia, comienzan a mostrarse algunas de las consecuencias de la forma en la cual se dio la guerra y se gestionó la postguerra. Para ello, desarrolla algunas cuestiones que cree centrales para abordar las controversias que genera el conflicto: cuáles eran las condiciones de quienes combatían, los planes de recuperación de la isla, los supuestos y condicionantes de la acción bélica, hasta la forma en que se dio el combate, la derrota y su incidencia en la salida democrática.

21 Lejos de hacer ucronía, Lorenz apuntala cómo Malvinas era ya una causa nacional que, en tiempos de naturalización de la violencia, no resultaba tan alocado recuperar por la fuerza. Explicita cómo se subestimó el interés del Reino Unido por participar de la guerra, la cual ve-nía siendo planificada desde tiempo atrás, y, cómo el relato -vuelto sentido común- que dice que esto fue una búsqueda de legitimidad entre los argentinos, deja de lado otros condicionantes importantes, como la situación internacional y la presión británica. A su vez, así como muestra el amplio arco de consenso sobre la recuperación, da cuenta de cierta oposición a la guerra, poco conocida y difundida, sobre todo teniendo en cuenta un escenario dictatorial donde no era gratuito oponerse públicamente.

En definitiva, podemos aseverar que Malvinas. Una guerra argentina, el más sintético y compacto de los tres libros, rompe con los lugares comunes y nos da respuestas sobre algunos de los nudos problemáticos que hacen que la guerra de Malvinas sea un evento difícil de codificar en la memoria colectiva de nuestro país. Luego de explicitar las temáticas de esta tríada de libros por separado, retornaremos sobre algunos elementos comunes que nos interesaron particularmente.

Corpus, Vol 1, No 2 | 2011 


\section{Sentidos del recuerdo. Alteridad y Malvinas}

Lorenz explicita más de una vez que el motor de su trabajo es la indignación por el silenciamiento y apropiación que se hizo del conflicto en distintos momentos, que generó casi tantas muertes después de junio de 1982 como durante esos 74 días de $1982^{4}$. Luego de estas lecturas podemos comprender que la forma en que se re-cuerda el conflicto bélico, sus muertos y cómo se trata a sus sobrevivientes ha dejado marcas físicas y psíquicas en los cuerpos, pero también en el territorio, no sólo en los protagonistas, en distintas localidades, sino también en el imaginario colectivo de nuestro país, en aquellos que se encuentran y encontraron directa o indirectamente vinculados con la guerra de Malvinas.

Frente a los 'caídos por la patria', sostienen algunos, no puede haber fisura. Solo el silencio, el respeto por su entrega" (2008, p. 136). Sin embargo, las formas en que se experimentó la guerra también nos devuelven imágenes heterogéneas que no sólo deberíamos revisar desde las ciencias sociales, sino también desde espacios sociales más amplios. Lorenz explica que "para analizar el desarrollo de los estudios sobre la guerra de Malvinas y, más ampliamente, de la guerra en la Argentina, es necesario prestar atención a las luchas por la memoria en relación con el conflicto (2011, p. 51).

Con el fin de la guerra, el autor afirma que existió un silenciamiento de las propias Fuerzas Armadas, que ante la derrota, intentaron esconder a los ex combatientes y sus marcas, mutilaciones y experiencias y comenzaron a buscar responsables individuales de la derrota o, incluso, a echarse culpas entre sí. Es en los años ochenta, y con continuidades posteriores, donde comienza cierta perplejidad ante el escenario de posguerra. Ahora bien, el gobierno militar no fue el único que dio respuestas in-adecuadas a los ex combatientes y sus dificultades, sino que tampoco los primeros años de democracia modificaron esto 5 . A pesar de lo que marcan Novaro y Palermo (2003), al contraponer las movilizaciones en torno a los desaparecidos y las organizaciones de derechos humanos y las de los ex combatientes, estas últimas no dejaron de existir por la misión nacional reconocida en la guerra, sino que, como bien marca Lorenz, su poca visibilidad tenía razón de ser en "su mancha de origen": eran víctimas, mutilados, muertos pero de una guerra llevada a cabo por una dictadura que había ejercido violencia contra sus propios ciudadanos, lo cual comenzaba a ser repudiado socialmente (2006, p. 127).

En este punto, hay algo central del planteo de Lorenz que resulta particularmente molesto para la historia, para ciertas posiciones académicas e, incluso, para la sociedad, y que lo ponen en un sitio de alguna manera "amenazante". Existen gran cantidad de análisis sobre las organizaciones armadas de los años setenta, de la experiencia de la dictadura, de las organizaciones de derechos humanos, del significado de los desaparecidos. Sin embargo, el silencio y la dificultad para pensar Malvinas y a los ex combatientes y sus organizaciones da cuenta no sólo de la complejidad de los hechos, sino también de cierta incomodidad para pensar las responsabilidades sociales por el lugar que tienen, tuvieron y tendrán, quienes combatieron, en nuestra memoria. Lorenz afirma que "formamos parte de sociedades que, post conflicto, han construido una imagen pacífica de sí mismas, lo que dificulta aún más la idea de que las guerras y las violencias fueron legitimadas y naturalizadas en otros momentos de la historia (inclusive por esas mismas sociedades)" (2011, p. 50). En este punto, Lorenz sostiene, a diferencia de otras miradas acerca del conflicto, que su investigación sobre Malvinas es "una aproximación al lugar de

Corpus, Vol 1, No 2 | 2011 
las juventudes en la política" (2006, p. 16), justamente en el caso de una generación que fue situada en un lugar de alteridad, que tuvo y tiene que resistir el espacio que les fue legado entre el silenciamiento y la apropiación de su experiencia, en los intersticios entre las "victimas" y el "Panteón" de los "héroes de la patria". En cambio,

El sentido común, aún el de muchos investigadores, todavía asocia la historia militar a descripciones de armas, batallas, cuestiones técnicas y relatos de idas y venidas diplomáticas. Esta forma de reconstrucción histórica, asimismo, alimenta ciertas formas de usos públicos del pasado (...) Este sentido común se potencia con la incomodidad que genera un elemento constitutivo de la experiencia de guerra: el hecho de que a lo largo del tiempo las sociedades han aceptado y legitimado distintos grados y formas de violencia aplicada a otros seres humanos, así como justificado las muertes de propios y ajenos (2011:49)

27 Aún cuando las organizaciones y movilizaciones de ex combatientes y familiares compartían con las de derechos humanos "el ser afectados por la violencia descargada sobre los hijos" (2011, p. 58), se subsume la guerra a la dictadura en diferentes lecturas y explicaciones de las ciencias sociales ${ }^{6}$, invisibilizando la experiencia de la guerra y subalternizando a toda una generación, cuya voz política es inmediatamente identificada con un nacionalismo radical o hasta con una defensa de la dictadura, cuando Lorenz nos permite ver que no son lo mismo las generaciones que fueron a la guerra como conscriptos y aquellos que estaban haciendo carrera militar y eran parte de unas Fuerzas Armadas que habían llevado adelante las violaciones a los Derechos Humanos. Estos jóvenes fueron retratados como "otros" dañados, tratados, antes como víctimas, pero no como sujetos activos de la historia reciente de nuestro país, por el trauma de la derrota, pero sobre todo por la responsabilidad no asumida socialmente. En definitiva, el no tratamiento de estas diferencias dejó lugar a que otros sectores, como las Fuerzas Armadas, pudieran apropiarse, en cierta forma, de la experiencia de la guerra, recuperando cierta legitimidad luego de lo que significó la última dictadura militar.

En estos jóvenes la huella de la alteridad fue marca-da por el silenciamiento de la experiencia de la guerra, que aún más fuerte que cualquier otra pertenencia, los hacía parte de esa "comunidad de combatientes" que Weber postula en años de la Primera Guerra Mundial como parte de un "un pathos y un sentimiento de comunidad", "una comunidad de sacrificio" marcada, justamente, por la experiencia misma de la guerra (1987, p. 446). El extremo de este silenciamiento es la falta de testimonios de ex combatientes en juicios a los represores, aún siendo considerados víctimas de la dictadura, la falta de enjuiciamientos a quienes llevaron adelante de-terminadas prácticas en las islas, llegando hasta la falta de publicación del Informe Rattenbach, informe oficial que daba cuenta de las actuación de las Fuerzas Arma-das durante la guerra.

29 Si bien hoy puede sonar extremo afirmar que todos los ex combatientes fueron subalternizados por las marcas de la guerra, podemos dar cuenta de cómo esa experiencia fue subalternizada, alejada de los relatos de la historia oficial y académica, no comprendida e invisibilizada. Claro que, todavía hoy, las distintas organizaciones de ex combatientes luchan por cierta comprensión del conflicto, por la memoria de los caídos en las islas y aquellos que, a pesar de haber sobrevivido a esos 74 días, nunca volvieron. 


\section{Postdictadura y Postguerra}

\section{Lorenz restitue el sentido colectivo que tomó la guera con las movilzaciones a favor,} Lorenz restituye el sentido colectivo que tomó la guerra con las movilizaciones a favor, incluso con la aceptación de las organizaciones armadas contrarias al régimen y reprimidas por el miso; sin embargo, tamiza esto a través de las diferentes experiencias. Rescata, en particular, la diferencia entre las ciudades patagónicas próximas al escenario del conflicto, que vivenciaron en forma más real la guerra, y Buenos Aires o "el Norte" donde "se vivía otra guerra, si es que existía la sensación de que había una" (2006, p. 79). La fórmula que resume esto fue: "la guerra se vivió del Colorado para abajo" (2008, p. 66). Tan es así, que varias ciudades del sur del país vieron afectada su vida cotidiana, en cierta continuidad con lo que había pasado cuando se estuvo cerca de un conflicto con Chile, generando incluso bronca el optimismo que se mostraba en Buenos Aires.

Corpus, Vol 1, No 2 | 2011 

forma diferente el conflicto, no sólo porque allí se dio "el final de la guerra de Malvinas, concentrado simbólicamente en el desembarco de los prisioneros" (2006, p. 84), en el cual la población rompería los cercos armados por las Fuerzas Armadas para que no tuviera contacto con los ex combatientes, sino porque allí la memoria permanece más activa, viva, como se vio en el "Madrynazo", el 10 de septiembre de 1984, cuando miles de personas impidieron que un barco estadounidense anclara en el puerto en repudio por el apoyo a Gran Bretaña en la guerra (2006, p. 290). A su vez, podemos ver cómo este recuerdo se reactualiza constantemente, por ejemplo, en la discusión sobre un proyecto de ley provincial en la Provincia de Chubut que prohíbe que barcos británicos con fines específicos amarren en los puertos de Chubut. ${ }^{7}$ Cabe agregar que esto ya fue aprobado en Santa Cruz y Tierra del Fuego, las provincias más australes de nuestro territorio.

Sin embargo, por la misma historia de las regiones y la vinculación entre éstas y las Fuerzas Armadas, no fue tan sólo la Patagonia la que vivió en forma diferencial el conflicto por estar cercana o dentro del TOAS (Teatro de Operaciones del Atlántico Sur), sino que el Nordeste y la Mesopotamia fueron otros ejemplos distintos de vivencia del conflicto. De allí salieron varias de las compañías que combatieron en las islas "con el 10\% de la población nacional, proveyeron el 30\% de los contingentes movilizados" (2011, p. 59). A su vez, Lorenz nos muestra cómo estas regiones tuvieron una sobrerrepresentación de muertes en combate, en relación con la población que re-presentan a nivel nacional (2009, p. 200). De esta manera, nos abre el campo para comprender cómo los estudios regionales sobre la experiencia de guerra podrían complejizar ciertas miradas porteñocéntricas, no sólo sobre el conflicto, sino también sobre la dictadura, permitiéndonos comprender mejor la vigencia de la memoria de guerra y el nacionalismo en la Patagonia.

\section{Historia y memorias abiertas}

La indagación histórica y la pregunta permanente pueden ser el lugar para encontrar en Malvinas a aquellos que me-recen ser castigados y recordados en su ignominia, que es un ejercicio de memoria activa tanto como el opuesto, aquel que significa reconocer a quienes deben ser honrados y res-petados por poner en riesgo sus vidas a cuentas de palabras añejas y cargadas de sentidos, como la patria, el honor y el deber, o la simple dignidad, tanto en la guerra como en la posguerra. Son conceptos que suenan anacrónicos en este presente fugaz, pero encierran a la vez herramientas de opresión y de liberación, $\mathrm{y}$, sobre todo, son una pregunta acerca de la propia responsabilidad frente al pasado y el futuro (Lorenz, 2009, p. 202)

A pocos meses de que se cumplan 30 años del desembarco en las islas, no encontramos aún una mirada hegemónica respecto de la guerra. Malvinas sigue siendo una causa nacional y se debate sobre qué medidas tomar para no perder recursos naturales a manos de los británicos. Sin embargo, no hay un gran debate en torno a la memoria del conflicto, no precisamente por ausencia de miradas diferentes y enfrentadas. Al contrario, sin ser un espacio muy tematizado, se sigue guerreando, aunque de maneras silenciosas, obturadas. Aquellos jóvenes ya no lo son tanto, sin embargo aún quedan en sus retinas las imágenes de la guerra, de sus compañeros muertos allí o aquellos que murieron a causa del silenciamiento posterior. Su memoria sigue activa. 
nz ayuda a recuperar la complejidad histórica de la guerra como una experiencia vivida no sólo por los que combatieron allí, sino por sus familiares y aquellos que vivieron en regiones que vivenciaron la guerra. Con su aporte, la mirada pierde ingenuidad y se comprende qué sucede cuando detrás de una reivindicación del conflicto aparecen unos u otros. Asimismo, despliega una pluralidad de campos y sentidos que la investigación sobre la experiencia de la guerra, sus relatos y su memoria abren para la comprensión de temáticas relevantes para las ciencias sociales en nuestro país, desde su lugar en relación a los problemas de la identidad nacional, la experiencia política de las juventudes en los años ochenta, o la vida cotidiana en la última dictadura militar, hasta estudios regionales respecto a la conformación del Estado en lugares de fuerte presencia militar, como los antiguos territorios nacionales.

39

Hoy, por el momento histórico que nos toca vivir, nuestra sociedad no consentiría mandar a sus jóvenes a la guerra en contra del colonialismo británico instaurado en el territorio hace tantos años. Sin embargo, no todas las vidas tienen el mismo valor colectivo. Un indígena, un inmigrante limítrofe, un joven de una villa y (todavía) un ex combatiente, no valen lo mismo para la sociedad que un estudiante universitario, una madre o una niña. La violencia en la Argentina se torna más o me-nos visible según quien sea la víctima y el victimario, se nombra o se torna genérica, según quien la sufre y esto tiene un fuerte vínculo con nuestra memoria. Por ello, si bien vivimos en una sociedad que no tolera los grados de violencia de los años setenta, aún se debe cuestionar acerca de qué y cómo elige recordar, entendiendo su propia memoria como forma de pensar el presente y el futuro. Por ello, queremos concluir con unas palabras de Lorenz:

Repudio la guerra de 1982 pero me enorgullezco de mis compatriotas conscriptos que en Malvinas encontraron tiempo -mientras padecían la ineficacia de sus mandos, a veces a sus propios oficiales, y buscaban comida- para ser compañeros de sus compañeros y aun para combatir al inglés. Estoy orgulloso de los jóvenes conscriptos que salieron de su casa en lugares que ni siquiera figuran en los mapas porque aprendieron que era su deber. Los respeto porque después de la guerra, además, hallaron el tiempo no solo para enfrentar el silencio y la marginación, para difundir lo que habían hecho y velar la memoria de sus muertos, sino para que nadie la pisotee, ni con banalizaciones que los transforman a todos en Sargentos Cabrales en un extremo, ni con simplificaciones que los confinan a los campos de concentración presurizados de la república perfecta del otro, solo porque visiones limitadas ven en ello un peligro y en cada monumento a los caídos, un homenaje a Videla (2008, pp. 21-22).

\section{BIBLIOGRAPHY}

Balza, M. (2003). Malvinas. Gesta e incompetencia, Buenos Aires: Atlántida

Esteban, E. (1993). Iluminados por el fuego. Confesiones de un soldado que combatió en Malvinas, Sudamericana, Buenos Aires.

Gamerro, C. (1998). Las Islas, Simurg, Buenos Aires, 1998. 
Guber, R., (2001). ¿Por qué Malvinas? De la causa nacional a la guerra absurda, Buenos Aires: Fondo de Cultura Económica.

Guber, R. (2009). De chicos a veteranos. Nación y memorias de la Guerra de Malvinas. La Plata: Ediciones al margen.

Lorenz, F. (2006). Las guerras por Malvinas. Buenos Aires: EDHASA.

Lorenz, F. (2008) Fantasmas de Malvinas. Un libro de viajes. Buenos Aires: Eterna Cadencia.

Lorenz, F. (2009), Malvinas. Una guerra argentina. Buenos Aires: Sudamericana.

Lorenz, F. (2011). “El malestar de Krímov. Malvinas, los estudios sobre la guerra y la historia reciente argentina" en Revista Estudios ํㅜ 25, enero-junio 2011.

Novaro, M. y Palermo, V. (2003). La dictadura militar 1876-1983: del golpe de Estado a la restauración democrática. Buenos Aires: Paidos.

Weber, M. (1987). Ensayos sobre Sociología de la Religión. Vol. I. Madrid: Taurus.

\section{NOTES}

1. Podemos recuperar en este sentido y en forma particular, al igual que hace Lorenz, los libros de la antropóloga Rosana Guber ¿Por qué Malvinas? De la causa nacional a la guerra absurda (2001) y De chicos a veteranos. Nación y memorias de la Guerra de Malvinas (2009).

2. Entre las formas de expresión de estas tensiones podemos nombrar los levantamientos carapintadas liderados por Aldo Rico y Mohammed Ali Seineldín, ambos veteranos oficiales que combatieron en Malvinas, ciertos beneficios logrados por estos, expresiones de distintas organizaciones de ex combatientes que se diferenciaban de los oficiales y suboficiales como el Centro de Ex Soldados Combatientes de Malvinas.

3. El autor muestra como ejemplos libros como el de Martín Balza, Malvinas. Gesta e incompetencia (2003), Edgardo Esteban Iluminados por el fuego (1993) y Las Islas de Carlos Gamerro (1998), aunque a este último lo recupera especialmente por la complejidad de la experiencia de Malvinas que expresa en la ficción.

4. Según se estima durante el conflicto murieron 649 argentinos, mientras que los suicidios de ex combatientes estarían pasando los 450. Fuente: APF Digital, http://www.apfdigital.com.ar/ despachos.asp?cod_des=58318.

5. Una discusión importante pero no pertinente en este escrito sería preguntarnos por el hoy, teniendo en cuenta los hechos del 31/05/2011 sobre los ex conscriptos que no fueron a la isla. Fuente: http://www.pagina12.com.ar/diario/elpais/1-169246-2011-06-01. html.

6. Para una crítica de distintas explicaciones de la guerra de Malvinas llevada a cabo por distintos cientistas sociales ver el artículo de Lorenz "El Malestar de Krimov. Malvinas, los estudios sobre la guerra y la historia reciente argentina" (2011).

7. Según surge de las notas publicadas en el Diario de Madryn "Concejales apoyarían el proyecto de prohibir amarre de buques de bandera británica" y "Adelantan voto favorable a la prohibición de amarre de buques ingleses en Chubut" los días 5 y 7 de octubre de 2011 respectivamente. 


\section{AUTHOR}

\section{SERGIO ANDRÉS KAMINKER}

Centro Nacional Patagónico, Consejo Nacional de Investigaciones Científicas y Técnicas (CONICET), Argentina.

Correo electrónico: kaminker@cenpat.edu.ar 